\title{
Sexual Interactions and Sexual Infidelity
}

\author{
Paddy McQueen ${ }^{1}$ iD
}

Received: 7 September 2020 / Accepted: 22 January 2021 / Published online: 14 February 2021

(c) The Author(s) 2021

\begin{abstract}
This paper establishes what constitutes a sexual interaction between two or more people. It does this by first defining a sexual activity as one in which the agent intends to satisfy a sexual desire (i.e. a desire for sexual pleasure). To understand what it means to engage in a sexual activity with another person, it draws from Bratman's account of shared collaborative activity. A sexual interaction is defined as one in which two or more people engage in a sexual activity together, with the intention of satisfying a sexual desire (or some sexual desires) in a mutually responsive and mutually supportive way. The paper then uses this account to consider what things constitute sexual infidelity. The answer is a broad one: many things can count as sexual interactions and hence can be considered to be sexual infidelity. Contrary to what a lot of people think, this can include the private use of pornography.
\end{abstract}

\section{Introduction}

Many people engage in sexual activities, either alone or with another person (or persons). When two or more people engage in a sexual activity together, then they have a sexual interaction. ${ }^{1}$ However, how do we determine what counts as a sexual interaction? To answer this, we need to know what constitutes a sexual activity and what constitutes a sexual interaction, i.e. what is required for two people or more people to engage in a sexual activity together? Whilst some attention has been given to the first of these issues, little has been said about the second. ${ }^{2}$ One important reason for

\footnotetext{
${ }^{1}$ For the sake of ease, I discuss sexual interactions between two people. Whatever is said about them also applies to sexual interactions involving three or more people. As I discuss later on, a person can be part of a sexual activity without partaking in it (i.e. without having a sexual interaction). Thus, a sexual activity can involve two people without it being a sexual interaction. An example of this is rape.

2 On the nature of sexual activity, see, e.g., Nagel (1969), Solomon (1974), Goldman (1977), Gray (1978) and Soble (2006). Christina (2017) puzzles over what sexual activities count as "having sex", but she does not analyse the category of sexual activity itself or what constitutes a sexual interaction. Clearly, however, one can have a sexual interaction without having sex with someone. Thus, determining what things count as "having sex" will not determine what a sexual interaction is.
}

Paddy McQueen

paddy.mcqueen@swansea.ac.uk

1 College of Arts and Humanities, Swansea University, Singleton Park, Swansea SA2 8PP, UK 
examining this topic is its relevance for identifying sexual infidelity. Many of us are in exclusive relationships. Typically, this means that we have agreed not to engage in sexual interactions with people other than our partner(s). ${ }^{3}$ In order to know when this agreement has been broken, we need what constitutes a sexual interaction. ${ }^{4}$ However, there is little consensus on this issue. Whilst almost everyone thinks that penile-vaginal intercourse is sexual infidelity, people are much more divided on whether it also includes kissing, flirting, sexting, cybersex, stripteases, the use of pornography or sex with robots (Whitty 2004; Blow and Hartnett 2005; Scheutz and Arnold 2017; Rockman 2017; Negy et al. 2018). By determining if these things can count as sexual interactions, we can establish whether they should be considered to be sexual infidelity. ${ }^{5}$

The paper is structured as follows. I first define what counts as a sexual activity (Sect. 2). I then develop an account of sexual interaction, based upon Bratman's concept of shared cooperative activity (Sect. 3). Finally, I use this account to determine what counts as sexual infidelity (Sect. 4). The answer is a broad one: many things can be sexual infidelity. Contrary to what many people think, this may include the private use of pornography.

\section{What is a Sexual Activity?}

Two people have a sexual interaction when they engage in a sexual activity together. Thus, to establish what a sexual interaction is, we first need to know what counts as a sexual activity. However, there is no agreed upon definition of this. Soble (2006: 18-23) canvases a variety of options, including: reproductive activity; activities involving contact with a sexual body part; acts that produce sexual pleasure or sexual feelings (see Gray 1978); trying or intending to produce sexual pleasure; and activity that tends to fulfil the desire for the pleasure of physical contact (see Goldman 1977). He finds all of them wanting, primarily because they exclude some activities that most people consider to be sexual ones.

To make some headway, we can think of sexual activity either "externally" or "internally". An external definition focuses on the physical action itself: stroking a penis; rubbing a clitoris; penetrating a vagina or anus; kissing or licking a part of the body. The problem with this approach is that it struggles to differentiate between a doctor examining a breast and a lover caressing a breast. Similarly, a kiss or massage

\footnotetext{
${ }^{3}$ Infidelity is sometimes defined as having a sexual or romantic relationship with someone other than one's partner(s). I prefer "interaction" to "relationship" because the latter term implies a relatively longlasting affair, whereas one could commit infidelity by having a very brief sexual interaction with someone (e.g. sex with a stranger outside a bar).

4 This means that I do not address purely emotional or romantic forms of infidelity. Although an important topic, it is beyond the scope of the paper. See, e.g., Collins (1999) and Guitar et al. (2017).

5 Of course, couples in semi- or fully-open relationships can agree that some or all sexual interactions with other people do not count as infidelity. However, many couples-perhaps the majority of themhave agreed not to engage in any sexual activities with other people. They will therefore need to know what things should be considered to be sexual interactions.
} 
can be non-sexual or sexual. We could, of course, say that a doctor "examines" or "feels" a breast, rather than "caresses" it. However, the very same physical movements can be described using a variety of terms. The appropriate word is determined, at least in part, by what the person thinks they are doing. This suggests that we are better off with an internal definition, which focuses on what the activity is like for the person. This could involve a description of what the person is experiencing and/or a description of what the person is intending.

Gray thinks that the first of these determines whether something is a sexual activity. He argues that what makes an activity a sexual one 'is just the sexual nature of the pleasure deriving from it' (Gray 1978: 194). It follows that 'no activity is a sexual activity unless pleasure is derived from it' (Gray 1978: 194). However, there are two problems with Gray's view. The first is that some sexual activities can be pleasureless. To my disappointment, masturbating or having sex with my partner produces no sexual pleasure. Nevertheless, these seem like sexual activities. The second problem is how it understands the occurrence of unexpected sexual pleasure. Gray gives the example, drawn from Reuben (1971: 201-202), of women who worked in the garment trade. Apparently, the operation of treadle sewing machines could be utilised as a masturbatory technique, i.e., one that produced sexual pleasure. He tells us that those who made this discovery by accident 'would then have found themselves engaging in sexual activity quite unintentionally' (Gray 1978: 194).

However, it seems wrong to say that the women were engaging in a sexual activity when they made their discovery, i.e. the moment they realised they were getting sexual pleasure from working the machine. Imagine that I am giving a friend a massage. Unexpectedly, I find myself becoming sexually aroused. At this point, I am not engaging in a sexual activity. However, if I carry on because it will be sexually pleasurable, then I am. This is because I must intend that my activity is a sexual one. Contra Gray, I cannot inadvertently engage in a sexual activity. It is thus better to say that the women only engaged in a sexual activity when they knowingly operated the sewing machine in order to achieve sexual pleasure. Indeed, Gray (1978: 194) writes that 'to the extent that they so employed [the sewing machine], I think it is clear that they would... be said to be engaging in sexual activity'. This undermines his position-and supports my contention-for it is only when the women intend to satisfy a sexual desire that their activity becomes a sexual one. It is only a sexual activity when the machine is "so employed" by them.

This indicates the importance of intention for determining whether something is a sexual activity. Specifically, an activity is a sexual one when the person engaging in it intends to satisfy a sexual desire. What is a sexual desire? There are several different views on this. Goldman (1977: 268) defines it as 'desire for contact with another person's body and for the pleasure which such contact produces'. Nagel (1969: 8) describes sexual desire as 'a feeling about other persons'. Specifically, it involves a complicated structure of reciprocal desire and recognition, in which (among other things) I desire another person and desire that they desire me, and desire that they be aroused by my desire for them, and that we are each aware of our respective desires (Nagel 1969: 12). The problem with both of these accounts is that they define sexual desire as necessarily interpersonal. However, sexual desire need not be about or involve another person. I may, for example, desire to masturbate simply because 
it feels sexually pleasurable. This involves no thought of contact with another person's body or mutual recognition of reciprocal desire. Similarly, some exhibitionist, voyeuristic and zoophiliac sexual desires need not involve reference to another person. So long as we think that activities such as masturbation can be sexual ones, then we ought to avoid thinking that sexual desire must, or even should, be interpersonal (Soble 1991). ${ }^{6}$

Given these issues, Primoratz (1999: 46) understands sexual desire to be the desire for certain bodily pleasures'. Specifically, it is the desire for sexual bodily pleasures. This seems right as an account of sexual desire, not least because it accommodates a wide range of sexual desires and avoids requiring that sexual desire is interpersonal. However, we need an account of what sexual pleasure is. Pleasure is a complex phenomenon and there are many different forms of it. ${ }^{7}$ How should we characterise sexual pleasure? First and foremost, sexual pleasure is a pleasurable sensation: pleasurable sexual activity feels nice. However, many non-sexual pleasures also feel nice, such as drinking coffee or soaking one's feet after a long walk. Primoratz (1999: 46) argues that what makes something a sexual pleasure is that it is connected to the sexual parts of the body, especially the penis, vagina and clitoris. Along similar lines, Shaffer (1978: 186) defines sexual satisfaction-which he treats as akin to sexual pleasure-as sexual arousal, which 'is state of the body in which the sexual areas, the parts of the body that distinguishes the sexes, undergo certain typical changes and the subject has typical sensations which are the awareness of these events'.

This also seems right. We experience pleasure as sexual when it involves the sexual parts of the body (Abramson and Pinkerton 2002). This is what enables us to identify it as a sexual pleasure. By "involves" I mean that the pleasurable sensation is located in them and they are physiologically active during the experience of the pleasure. Generally speaking, stroking a clitoris or a penis generates the pleasant sensations constitutive of sexual pleasure (at least if done well). People can also derive sexual pleasure from other, non-sexual parts of the body, such as the toes, lips or ears. However, this still involves pleasurable sensations in the sexual parts of the body, along with physiological changes in them (e.g. an erection or vaginal lubrication). ${ }^{8}$ Thus, a kiss or a massage can produce either sexual or non-sexual pleasure, depending on whether it generates pleasurable sensations in the sexual parts of the

\footnotetext{
${ }^{6}$ Nagel could argue that he is offering a paradigmatic or normative account of sexual desire, rather than identifying the essential element of sexual desire. If so, he does not justify why the complex account of reciprocal, interpersonal desire that he describes should be the paradigmatic or normative form of sexual desire. Even if Nagel's account can include masturbation as a sexual activity, it would still deem masturbating on one's own to be a perverted sexual activity (Soble 2002: 78).

7 For example, Goldman (2016) distinguishes pleasure as physical sensation, pleasure as enjoyment, pleasure as an overall feeling or mood, and pleasure as an attitude. Similarly, compare the pleasure of eating an ice-cream with the pleasure of reading a good book, dancing at a gig or sexual intercourse.

8 Sexual pleasure, as a distinct type of pleasure, may also involve specific parts of the brain, such as the hypothalamus. However, it is not known whether the firing of certain neurons always produces sexual pleasure / demarcates a pleasure as sexual. As Abramson and Pinkerton conclude after reviewing the scientific literature, "Is sexual pleasure synonymous with the firing of particular neurons? We simply don't know' (Abramson and Pinkerton 2002: 91). What does seem certain is that sexual pleasure involves the sexual parts of the body.
} 
body. These sexual sensations can range from very subtle, such as a gentle tingling, to very strong, such as when one orgasms.

According to this view, whether or not a pleasure is a sexual one is involuntary; I cannot will that something is or is not sexually pleasurable. Sex can fail to be sexually pleasurable, despite my sexual desire, and a friendly massage can be inadvertently sexually pleasurable. It is also worth noting that sex can be pleasurable in nonsexual ways. It can be fun, interesting and exciting; it can be physically pleasurable in the way that physical exercise is; it can be a source of malicious pleasure, for example if I have sex with the partner of someone I dislike in order to make her suffer or as an act of revenge. Such non-sexual pleasures can co-exist with sexual pleasure, but they are not themselves sexual pleasures.

It follows from all this that a sexual activity can be defined as one in which I intend to satisfy a sexual desire, either in myself or the person(s) with whom I am engaging in sexual activity, which is a desire for sexual pleasure (i.e. pleasurable sensations directly or indirectly involving the sexual parts of the body). This does not have to be my only intention; I may also engage in the activity in order, for example, to procreate, to lose my virginity or to get some exercise. Rather, it must be one of my intentions. This is a very inclusive view. Pretty much any activity can count as sexual, so long as it is performed in order to produce sexual pleasure either in myself or the person(s) with whom I am engaging in sexual activity. People's sexual tastes are very varied, especially when we consider some of the rarer fetishes. If an object or situation gives someone sexual pleasure, then an activity which involves it can be a sexual one. Furthermore, I do not have to experience sexual pleasure for the activity to be a sexual one; my sexual desire or that of my sexual partner does not have to be satisfied. What matters is my intention to satisfy it. The account can therefore deal well with the case of pleasureless sexual activity, in which I intend, but fail, to experience sexual pleasure.

It may be objected that the account runs into the problem of desireless sexual activity. Desireless sexual activity lacks any intention on the part of the agent(s) to produce sexual pleasure. Consider a couple who have no sexual desires for one another but who have sex only in order to procreate or to consecrate their marriage. Their intention is, say, to perform a religious duty, rather than to produce sexual pleasure. Nevertheless, this still seems to be a sexual activity. In response, I argue that one can have sexual intercourse without engaging in a sexual activity. A couple can have "reproductive sex" without having, for want of a better term, "sexual sex". After all, there is no sexual desire; there is no intention to experience sexual pleasure. ${ }^{9}$

To support this claim, consider a teenage boy who wants to measure the size of his penis. He strokes his penis in order to make it erect. His only intention is to measure its size; he has no intention to experience sexual pleasure. I think it right

\footnotetext{
9 The sexually desireless couple could choose to have sex solely in order to procreate and discover during this that they are finding it sexually pleasurable. If they choose to carry on, then they are now intending to have sex (partly) in order to satisfy a sexual desire. At this point, their sex becomes a sexual activity.
} 
to say that this is not a sexual activity, even though it involves the same physical action—stroking the penis_-as masturbating for sexual pleasure. To give a second example, rape can involve the purely physical act of sexual intercourse. However, the victim is not engaging in a sexual activity. Most cases of rape will be a sexual activity for the rapist, because he or she is acting on a sexual desire, i.e. he or she intends to experience sexual pleasure. ${ }^{10}$ However, this need not be the case. A soldier may rape an enemy as a form of punishment, revenge or torture, without having or seeking to satisfy any sexual desire. The victim and rapist have had nonconsensual sexual intercourse, but neither was engaging in a sexual activity. Finally, actors can perform naked sex scenes together, in which they kiss, caress and the like. If they are solely acting and are devoid of sexual desire, then this is not a sexual activity. $^{11}$

\section{Sexual Interactions as Shared Cooperative Activity}

A sexual interaction occurs when two or more people engage in a sexual activity together. I have defined "sexual activity" as an activity involving the intention to satisfy sexual desire (i.e. to produce sexual pleasure). We thus need to identify what is required for two or more people to intend to satisfy sexual desire(s) together.

It is important to note that not every sexual activity involving more than one person counts as a sexual interaction. As Gray (1978: 193) notes, 'there is nothing intrinsically objectionable in the suggestion that what is, from the point of view of one of the participants, a sexual activity, may not be so from the point of view of the other'. The clearest example of this is rape. ${ }^{12}$ The rapist and victim do not have a sexual interaction, even though the physical act of sexual intercourse occurs. Instead, rape involves the mere use of someone within another person's individual sexual activity. ${ }^{13}$ The sexual activity happens to the victim, rather than the victim engaging in it. This means that someone can be part of a sexual activity without partaking in it. Furthermore, two people can be engaged in the same activity without thereby doing that activity together. Bratman (1992: 327) gives the example of two people painting the same house. They need not be doing this cooperatively or even with an awareness of the other's activity (perhaps they are each painting different sides of the house, ignorant of what the other is doing). To give a sexual example,

\footnotetext{
${ }^{10}$ It is possible, albeit unlikely, that a rapist intends to produce sexual pleasure for their victim, rather than for them to experience it. This would also be a sexual activity for the rapist, given their intention, but not for the victim.

11 This means that someone who has sex solely for the pleasure of revenge or the pleasure of a novel experience is not engaging in a sexual activity, because they have no intention to experience sexual pleasure. Such cases are extremely unlikely, as most people will have sex, at least in part, in order to experience sexual pleasure.

12 Although I would not say that the victim of rape is a "participant" in the activity, given that this term generally denotes that one is actively involved in something (and, typically, has chosen to be involved in it).

13 Assuming, as noted above, that the rapist intends to produce sexual pleasure.
} 
consider two people masturbating in the same bed. It need not be case that they are masturbating together. Neither may know that the other is masturbating, provided the bed is big enough and each is sufficiently discrete.

Consequently, to determine what a sexual interaction is, we need an account of when a sexual activity can be said to be a joint or shared one. To develop this, we can utilise Bratman's account of shared cooperative activity (SCA) (Bratman 1992; 2014). He identifies three requisite features of SCA: (i) mutual responsiveness; (ii) commitment to the joint activity; (iii) commitment to mutual support (Bratman 1992: 328). Mutual responsiveness means that each participant 'guides his behavior with an eye to the behavior of the other, knowing that the other seeks to do likewise' (Bratman 1992: 328). Commitment to the joint activity means that each participant has an intention in favour of the activity they are engaging in (Bratman 1992: 329). This requires that their reason for what they are doing must involve reference to the other person involved. Each intends to do something with the other person. In addition, they must have "meshing subplans" (subplans being additional intentions relating to the activity). For their subplans to mesh, they be mutually realisable. Clashing subplans prevent something from being SCA. To give Bratman's example, both of us may intend to paint the house together, but I intend to paint it red and you intend to paint it blue. We may end up painting the house together-perhaps a mixture of red and blue-but ours was not SCA (Bratman 1992: 331). ${ }^{14}$ Commitment to mutual support means that we are committed to helping the other engage in SCA. Finally, it will be common knowledge between the participants that they each meet the requirements of (i), (ii) and (iii).

My definition of sexual activity centred upon intention: a sexual activity is one in which the agent intends, among other things, to experience sexual pleasure. This fits well with Bratman's account of SCA. Putting them together, we can say that a sexual interaction is one in which two or more people willingly engage in an activity with the intention of satisfying a sexual desire (or some sexual desires) in a mutually responsive and mutually supportive way. In short, they interact in order to produce sexual pleasure for one or more of them.

To make this clearer, consider a paradigmatic sexual interaction: Sarah and Paul have penile-vaginal intercourse in order that they both experience sexual pleasure. This will be a sexual interaction if:

A. They both monitor and respond to the intentions and actions of the other, knowing that the other is similarly responsive. For example, Sarah might undress in the expectation that Paul will, and vice-versa; they might coordinate their bodily movements during sex and adjust them as needed; they might check whether what they are doing is enjoyable for the other person, etc.

\footnotetext{
${ }^{14}$ We may not initially have clashing subplans, but these could emerge as we engage in an activity together. For this to continue to be SCA, we would need to negotiate in order to resolve the clash. This indicates the importance of the first requirement, mutual responsiveness.
} 
B. They both intend that engaging in penile-vaginal intercourse will be sexually pleasurable for each of them. At least one of their reasons for having sex is to achieve this goal. Furthermore, they are mutually responsiveness in pursuing it.

C. They have meshing subplans. Imagine that Sarah has the subplan of recording their having sex together and posting this online, whilst Paul intends that their sex is a private affair. Alternatively, Paul might have the subplan of having sex in order to reproduce, whilst Sarah will only have sex if they use contraception. If neither is willing to change these plans so that they do mesh, then they cannot engage in a sexual interaction with one another.

D. They are both committed to supporting one another to achieve their intentions. In a sense, this is already contained in (A), where Sarah and Paul monitor what they are doing to see whether it is pleasurable for the other person and will adjust their behaviour accordingly. However, (D) also includes dispositions to act in supportive ways. For example, if Paul were to lose his erection, then Sarah will be willing to help him to regain it. If Sarah needs a short break, then Paul will be willing to have one.

E. It is common knowledge between Sarah and Paul that (A)-(D).

There are some important clarificatory points to make about this account. First, neither Sarah nor Paul need be successful in realising their intentions. It is possible that neither experiences sexual pleasure, or that only one of them does. What matters is the intention to satisfy the desire for sexual pleasure, rather than success in this endeavour. Second, the intention to satisfy sexual desire need not be their only reason for engaging in the activity together. For example, Sarah and/or Paul may also intend to improve their physical health through the activity. Where they do have other intentions, these must "mesh", i.e. be compatible. Third, Sarah and Paul need not intend that they both experience sexual pleasure. What is required is that they intend to satisfy a sexual desire together. Perhaps only Sarah desires sexual pleasure. They could thus have a sexual interaction in which Paul performs cunnilingus on Sarah purely for her pleasure. Neither of them needs to intend that Paul finds this sexually pleasurable. What is required is that they both intend that Sarah does.

To give another example, I may hire a sex worker to satisfy my sexual desire. She need not have any sexual desire herself in order for us to have a sexual interaction. That is, she need not intend that she experiences sexual pleasure. What matters is that we have the shared intention that I experience sexual pleasure. This means that she acts in a way that is responsive to my sexual desire and aims to satisfy it, as demonstrated, for example, by her engaging in the sex acts we have agreed she will engage in. This is compatible with her also intending to earn money, which might 
well be her primary reason for having sex with me. As Bratman (1999: 122) notes, there can be shared intentions 'even when the agents have different reasons for participating'. What is required is that these other intentions are compatible with the intention to satisfy my sexual desire. For example, I am willing to pay her for sex. ${ }^{15}$

It could be objected that the sex worker might only desire that she gets paid. She might be utterly indifferent as to whether I experience sexual pleasure and hence has no intention that I do so. If so, then my account denies that we are having a sexual interaction. In response, I argue that there is still a sense in which the sex worker intends that I experience sexual pleasure. She willingly and knowingly engages in an activity that aims to satisfy my sexual desire. She need not care about me experiencing sexual pleasure, in the sense of being emotionally affected by it, but she is aware that she is partaking in an activity to satisfy a sexual desire (after all, that is what I am paying her for). She also coordinates her actions with mine in order to ensure the activity is successful in this regard, from undressing to monitoring bodily movements in response to mine during sex. Thus, she intentionally takes part in an activity that aims, among other things, to produce sexual pleasure for me. Indeed, it is quite possible that she will intend me to orgasm as quickly as possible, so that the interaction is over sooner.

Fourth, and relatedly, people can have a sexual interaction even when they each use the other for their own sexual pleasure. Two people may masturbate in front of each other, using the other as a stimulus for their own pleasure and having little regard for whether the other person experiences sexual pleasure. This is still a sexual interaction, because they are engaging in an activity together in order to satisfy their respective sexual desires. They are still masturbating together, even though each is focused on his/her own pleasure. (compare this case to the example of two people in the same bed who are each unaware that the other masturbating, which is not SCA).

Fifth, someone does not need to be active within a sexual interaction. Morgan describes a practice that was apparently popular in certain San Franciscan bathhouses in the 1970s and 1980s. In these bathhouses, 'men could be found lying face down on benches in side rooms with their heads covered by towels. Other men would enter, mount and penetrate a prone man, in due course ejaculate, withdraw and leave' (Morgan 2003: 9). This situation can be described in such a way that it meets the requirements for being a sexual interaction. We can assume that the men intend to experience the pleasure of anal sex and guide their behaviour in relation to one another (e.g. the man is lying there waiting for someone to penetrate him, rather than simply resting or trying to sleep). Furthermore, their intentions are common knowledge: they know that they intend to have anal sex (although this is not explicitly stated, it is indicated via established conventions and the context). Thus, someone does not need to do much to be part of a sexual interaction. To give another

\footnotetext{
15 By analogy, I can pay Georgia to help me paint my house. This can be SCA, even if her reason for painting the house with me is to get paid. We can still intend that we paint the house together, despite our diverging reasons for this.
} 
example, imagine that I hire a sex worker to stand in front of me naked, so that I can look at her whilst masturbating. Despite the absence of physical contact and active engagement, this can still amount to a sexual interaction. ${ }^{16}$

Sixth, sexual interactions can take place across physical distances. Consider a non-sexual SCA: Chloe and Sadio are academics who live in different countries. Despite this, they are writing a journal article together, exchanging ideas via email and editing a collaborative document. They are mutually responsive to each other and mutually committed to the activity. They are thus engaged in a single, joint activity. To give an example of a sexual interaction, imagine that Olivia lives in Glasgow and her partner Claire lives in Paris. One night they hold a video call so that they can mutually masturbate in front of each other. Their intention is that they should satisfy their sexual desires, which in this instance is for the pleasure of masturbating whilst watching the other masturbate. They are not engaging in two distinct sexual activities, which just happen to be occurring at the same time. They are engaged in a single activity together.

Finally, seventh, sexual interactions can be of significant duration. Imagine that, instead of holding a live video call, Olivia and Claire record and send each other videos of themselves masturbating. They then masturbate whilst watching the other's video. Their joint intention is that they should experience sexual pleasure from watching these videos whilst masturbating. Furthermore, they guide their behaviour with an eye to one another. Each sends their video, expecting that the other will do the same. They tailor their behaviour in the video to the other, perhaps talking to them or wearing clothing they find attractive. This should be thought of as a single, ongoing activity that they are engaging in, rather than a series of discrete events. To support this claim, consider the above example of Sadio and Chloe co-authoring a paper. Although they are not always working on the paper, they would still consider themselves to be engaged in this activity together. If someone asked Sadio how long he and Chloe had been writing the paper for, he would work it out from the time they first started working together. Their activity together is ongoing so long as they both (a) retain the joint intention; (b) remain mutually responsive; (c) remain mutually supportive; (d) have meshing subplans; and (e) know that each of them knows that (a)-(d) is satisfied.

To sum up, we can define a sexual interaction as a sexual activity involving two or more people, in which the participants (i) intend, among other things, to satisfy one or more sexual desires, i.e. desire(s) for sexual pleasure; (ii) are mutually responsive to one another in satisfying the sexual desire(s); (iii) are mutually supportive of one another in satisfying the desire(s); (iv) having meshing intentions; and (v) conditions $\mathrm{i}-\mathrm{iv}$ are common knowledge among the participants. On this account, sexual interactions can take place across significant geographical distances and periods of time. In the next section, I use this account to identify what does and does not count as sexual infidelity.

\footnotetext{
${ }_{16}$ Provided it meets the conditions of mutual awareness and mutual support. For example, she knows that I am watching her for my sexual pleasure, she ensures that she is standing in my line of sight, she undresses for me, we have agreed that I will pay her for this, etc.
} 


\section{Identifying Sexual Infidelity}

I have defined a sexual interaction as a sexual shared cooperative activity. Given that someone in an exclusive relationship commits sexual infidelity if they have a sexual interaction with a person other than his/her partner, then anything which constitutes a sexual SCA is sexual infidelity. This means that things such as phone sex and mutual masturbation can be sexual infidelity, if people engage in them together in order to produce sexual pleasure for one or more of participants. More controversially, a striptease or a pole dance can be cheating, depending on the situation. If I ask someone to perform a striptease for me, so that I can experience sexual pleasure, and she or he agrees to this, then we will have a sexual interaction. In contrast, if it is my hen do and I discover that my bridesmaid has hired a stripper for me, then the stripper and I do not engage in a sexual activity together if we do not intend to produce sexual pleasure for one or both of us. It may be intended and experienced by both of us to be harmless, non-sexual fun (enjoyable, but in a non-sexual way), in which case this is neither a sexual interaction nor a sexual activity for either of us.

Alternatively, it is possible that the stripper intends this to be sexually pleasurable for me, but I have no sexual desire. Instead, I find it an uncomfortable, unenjoyable, wherein my sole intention is to endure it because I do not want to be a spoil sport. In this case, it is a sexual activity for the stripper, but it is not a sexual interaction; I am not partaking in a sexual activity with the stripper. It could, of course, turn into a sexual interaction, were I to derive sexual pleasure from it and continue to engage in it. If it does, then I cannot avoid the accusation of sexual infidelity by saying that I did not want or ask for the striptease in the first place. However, being part of a striptease does not automatically constitute a sexual interaction and thus is not necessarily sexual infidelity.

In his discussion of online relationships, Ben-Ze'ev (2004) argues that we can consider online erotic interactions, such as the use of adult chat rooms, to be a form of infidelity. His justification for this is that such interactions, especially when they involve masturbation, contain many of the 'basic characteristics of actual sex... excitement, anticipation, satisfaction, and orgasm' (Ben-Ze'ev 2004: 204). I agree with Ben-Ze'ev's conclusion that online activities can be sexual infidelity but not because they contain some basic characteristics of "actual sex". We should not judge whether something is sexual infidelity on the basis of its resemblance to "actual sex". Rather, what matters is whether the participants intend to produce sexual pleasure through the joint activity. Afterall, as with the above case of pleasureless sex, it is possible that the basic characteristics of sex do not happen during an online sexual interaction. I might be very bad at such interactions, failing to produce any sexual pleasure for myself or the person I am interacting with. The activity may be devoid of things like "satisfaction and orgasm". Nevertheless, if the joint intention and requisite interpersonal attitude are there, then we are having a sexual interaction and thus committing sexual infidelity.

It is worth contrasting my broad account of sexual infidelity with a restrictive one. Portmann discusses the phenomenon of 'anonymous dirty talk' between 
people via the Internet or phone. He argues that these things are not infidelity because talking about sex with people is different in kind to having sex with them (Portmann 2017: 86). Consequently, an erotic online conversation between people who are in exclusive relationships is not infidelity, but rather akin to flirting. ${ }^{17}$ This rests on Portmann's assertion that to cheat on someone, you must have sex with them, and sex 'entails skin-to-skin contact' (Portmann 2017: 91). More specifically, cheating must involve penetration: 'In a sea of ambiguity, penetration emerges as the best single criterion of cheating we may expect to find' (Portmann 2017: 97). Portmann's argument should be rejected. As we have seen, a sexual interaction need not involve physical contact. Two people in exclusive relationships may mutually masturbate in front of each other in order to experience sexual pleasure. If they do this, then they are guilty of sexual infidelity, even though neither penetrates the other and they have no skin-to-skin contact.

Finally, what about the private use of pornography? ${ }^{18}$ Many people deny that this can be sexual infidelity. ${ }^{19}$ Portmann (2017: 98) does so, on the basis that it does not involve skin-to-skin contact (specifically, penetration). His position is flawed, as sexual interactions need not involve skin-to-skin contact. Nevertheless, one may still argue that the use of pornography does not constitute a sexual interaction; it is not an activity that two or more people do together. This is the position of Woollard (2010). She argues that there is no 'real interaction' between the person viewing pornography and the person(s) being viewed. The private use of pornography does not involve 'sexual intercourse', which she defines as 'sexual interaction between two or more persons' (Woollard 2010: 96). Instead, Woollard construes the use of pornography as a form of fantasising, in which one imagines having a sexual interaction with someone, but no such interaction takes place. There is, she insists, 'all the difference in the world' between fantasising about sex with someone and having sex with them (Woollard 2010: 97).

The nub of Woollard's argument is that private use of pornography is not something people "do together". However, on the account of sexual interaction as SCA that I have developed here, this is not necessarily the case. Nowadays there are forms of interactive pornography, such as live streams of an individual or people engaging in sexual activities. Viewers can communicate with them via chat boxes, including suggestions of things for them to do. They therefore do interact with the person(s) in the live video. The viewer and performers have the shared intention of satisfying sexual desire and they are mutually responsive to each other in achieving this. What they are doing meets the requirements for their

\footnotetext{
17 On my account, flirting need not be sexual infidelity, if it does not involve the intention to produce sexual pleasure. I think that some flirting falls short of being sexual in nature. It is can be playful rather than sexual, perhaps involving a boost to one's self-confidence rather than sexual arousal. Of course, some flirting does cross the line into sexual arousal, in which case it can be considered sexual infidelity.

18 By this, I mean watching pornography on one's own for sexual pleasure, typically whilst masturbating. Some couples may permit each other to use pornography in private, because they do not think it is sexual infidelity. I am providing some reasons why they may want to reconsider that belief.

19 For example, Negy et al. (2018) interviewed 658 undergraduate students in America and Spain. 75\% of participants said that viewing pornography did not constitute cheating on one's partner.
} 
activity to be a sexual interaction and hence people engaging in this can commit sexual infidelity. However, perhaps this is not what Woollard has in mind. She might allow that this is an example of sexual infidelity but deny that it counts as "the (private) use of pornography". Perhaps it is better described as participating in an interactive sex show, which may more readily be seen as cheating. Alternatively, one could allow that this is pornography but argue that what is not sexual infidelity is the more "typical" form of pornography, namely watching a recorded video on one's computer, which does not involve live interactions between the viewer and the performers. Is there a way that this can be construed as sexual SCA and hence sexual infidelity?

Here an attempt to do so. Recall Olivia and Claire, who exchange masturbation videos that they then watch for sexual pleasure. I showed that what they are doing can count as a sexual interaction. This means that if they are in exclusive relationships with other people, then they are committing sexual infidelity. Importantly, this would also be the case if only one of them was filming videos and sending it to the other person in order to satisfy their sexual desire. As we saw above, the joint intention of a sexual interaction can be to provide sexual pleasure for one person only. With these points in mind, compare the following scenarios:

S1: Julia and Sam meet online. Julia wants to experience sexual pleasure by masturbating whilst watching a video of Sam masturbating. She tells Sam this and asks him to record such a video. Sam does so and sends it to Julia. Julia masturbates whilst watching the video of Sam.

S2: Emily wants to experience sexual pleasure by masturbating whilst watching a video of a man masturbating. She goes onto a porn site and finds such a video. This video has been made by Mark, who posted it to the site for people to use for their sexual pleasure. She masturbates whilst watching the video of Mark.

On my account, Julia and Sam are having a sexual interaction. If one of them is in an exclusive relationship, then they are cheating on their partner. Those who deny that the private use of pornography is infidelity must deny that Emily and Mark are having a sexual interaction. If they are right, then what is the relevant difference between S1 and S2? It cannot be the fact that Emily and Mark do not know each other. We saw in the example of the San Francisco bath houses that strangers can have a sexual interaction. Perhaps the difference, then, is that Mark does not know that Emily is watching his video. Indeed, he does not know that Emily exists. It might seem a requirement of SCA that the people involved know of each other's existence. To test this assumption, consider the following scenario:

S3: SexShare is an online erotic video sharing group, which people sign up to anonymously. Group members can record themselves performing sexual acts and send this video to an administrator. The administrator then sends the video to another person in the group. Mike signs up to the group, receives a video and masturbates whilst watching it. The man in the video does not know that Mike is watching him; he does not even know that Mike exists. 
Is Mike engaged in a sexual activity with the man in the video? Both have the intention of satisfying sexual desire and hence of producing sexual pleasure. Both can assume they each have this intention, given that they have signed up to the group and the person in the video has recorded and distributed it. There may also be a sense in which they are responsive to each other. At the very least, the person in the video makes the video with an eye to the joint activity. Their reason for making it is to provide sexual pleasure for other people and they try to make the video sexually appealing. Furthermore, they can be disposed to be more responsive, should the opportunity arise-for example, they would use an anonymous chat function, if it were introduced and hence tailor their videos to requests. I am inclined to see this as a sexual interaction and hence as sexual infidelity. It can also be argued that this is pornography. A standard, basic definition is that it is material (e.g. books, films or photographs) depicting sexual behaviour that is intended to be sexually exciting. Thus, I think that S3 is an example of the use of pornography being sexual infidelity.

Perhaps one denies that this should be considered pornography, or at least one denies that it is "typical" pornography. Most pornography, one may claim, is what you find on popular Internet porn sites like Pornhub. However, even the use of these sites might count as a sexual interaction. Often performers in pornography videos are intending to satisfy viewers' sexual desires. That is at least partly why they make the videos. They may also make them in order to earn money or become famous. However, insofar as they try to make sexually appealing videos for viewers, and tailor them so that they are, then they intend that the videos produce sexual pleasure. ${ }^{20}$ There is, then, a sense in which the performers are at least minimally responsive to the viewer, as they make the videos based on what they think the viewer will find sexually pleasurable. They can also be disposed to be responsive, e.g. they would alter what they do in response to viewer feedback, to make their videos more sexually arousing. Given that people who watch the videos typically do so in order to experience sexual pleasure, it seems like the performer and viewer have the shared intention to satisfy the viewer's sexual desire.

This might constitute a sexual interaction between the performer and viewer, as I argued is the case in S3. However, it may not. Consider, then, that there are large porn conventions at which a fan can meet their favourite erotic actor. They may get to know one another, spending time chatting together. Alternatively, a fan may communicate with an actor via social media. They could tell the actor that they are looking forward to their next film. They could suggest future videos for the actor to make. In turn, the actor could let the fan know about the release of their latest video, even providing a link to it. Perhaps the actor incorporates some of the fan's suggestions into the video and tells the fan that they have done so. This sort of case starts to resemble closely $\mathrm{S} 1$. We might be-I would suggest should be-willing to see this as a sexual interaction. If so, then this is another instance of the private use of pornography constituting sexual infidelity.

\footnotetext{
${ }^{20}$ Recall that a person can have multiple intentions when engaging in a sexual interaction and the participants can have different reasons for partaking in it.
} 
This is, of course, a niche example. Most people do not go to porn conventions or communicate with erotic actors. Similarly, most people do not use live, interactive sex sites (although this might become more common as technology develops). For most people, a porn video is simply a stimulus for their own sexual pleasure. When watching the video, they do not intend to have a sexual interaction with someone; they have no thoughts about doing something with another person. Thus, it will be argued, they are engaging in a sexual activity, but they are not having a sexual interaction. If this is right, then on many occasions, the use of pornography is not sexual infidelity, because it is not a sexual interaction. The fact that other forms of pornography use can be sexual infidelity — as outlined above-is still an important conclusion. $^{21}$

It might also be thought that some solo sexual activities-i.e. sexual activities that are not sexual interactions - can be sexual infidelity, such as a person masturbating alone whilst imagining having sex with someone other than their partner. All sexual interactions with people other than one's partner(s) constitute sexual infidelity, but that need not exhaust the possible forms of sexual infidelity. A person might consider masturbating whilst watching a video on a porn site to be a solo sexual activity that is sexual infidelity. I argued above that someone who rapes a person for their sexual pleasure is engaging in a sexual activity, rather than a sexual interaction. This might still be seen to be sexual infidelity, even if (on my account) it is not a sexual interaction. I do not endorse this view, as I think that sexual infidelity must involve people engaging in a sexual activity together, i.e. it must involve a sexual interaction. $^{22}$ This is why, contrary to what some people think (Scheutz and Arnold 2017: 255), sex with sex-bots cannot be sexual infidelity, because they (at least currently) lack the cognitive ability and autonomy required to have sexual interactions. It is for the same reason that one cannot have a sexual interaction with an animal and hence bestiality is not sexual infidelity. Having sex with sex-bots and animals is a sexual activity, rather than a sexual interaction. If the private use of pornography is a solo sexual activity, then I do not think that it can be sexual infidelity. However, a more detailed discussion of whether only sexual interactions can be sexual infidelity is beyond the scope of this paper.

There are, of course, other forms of infidelity, beside sexual infidelity. Many people think that one can commit romantic or emotional infidelity (also known as "affairs of the heart"). This involves a person forming an excessively intimate, emotional relationship with someone other than their partner, although they have

\footnotetext{
${ }^{21}$ One might try to argue that even this standard use of pornography can be construed as a sexual interaction. One could claim that the porn actor chooses to post a video that others will use for their sexual pleasure, that the viewer watches the video in order to experience sexual pleasure, and that this can meet the requirements of a sexual SCA. However, I will not make that argument here.

22 This means that a rapist does not cheat on their partner when they commit their crime. This might be controversial, but I think it is right. After all, we normally assume cheating involves cheating on someone with another person and, in the case of rape, one does not have a sexual interaction with the victim (in the sense of them having sex together). It is possible that the rapist still wrongs their partner in some other way, just as one might feel betrayed if one's partner turned out to be involved in some other kind of serious wrongdoing. The use of pornography as a solo sexual activity might also wrong one's partner, even if it is not sexual infidelity, but I am not sure that it does.
} 
no sexual desire for one another. Perhaps we should create the category of "physical infidelity" to denote interactions that involve an excessive physical intimacy between two people who are devoid of sexual desires and hence do not engage in a sexual activity together. Actors performing a naked sex scene together might fall into this category. However, this is a tentative suggestion, which there is not space here to develop.

I will conclude by responding to two objections to my account and offering a clarification. The first objection concerns the focus on people's intentions in determining whether something is a sexual interaction and, therefore, whether something is sexual infidelity. Specifically, it can make it very hard to know whether something is sexual infidelity because we need to know what people's intentions are. This might be difficult to ascertain. I may discover that my partner is using adult chat rooms. She tells me that she is using it for her comic entertainment, rather than sexual pleasure. If it is the former, then my account denies that this is infidelity because it denies my partner is having a sexual interaction. This seems to give cheaters an easy way out: they just deny that they intended to satisfy sexual desire in their interactions with the other person(s).

I do not think that this is a problem for my account. If I walk in on my partner having sex with someone, it is easy to infer what their intentions are. In general, at least when it comes to sexual activity, there is often little difficulty in knowing what a person's intentions are. If I discover that my partner is exchanging erotic photos or videos with someone, it is reasonable to assume their intention is to experience sexual pleasure. She may deny this, in which case I must work out if she is telling the truth. However, most cases of sexual infidelity are going to be clear cut. Furthermore, this issue is not about the plausibility of the account itself, but the fact that people can lie about their intentions. ${ }^{23}$

The second objection is that my account implies that sexual infidelity does not occur if people have desireless sex, because this is not a sexual interaction. Rather than being a problem, I think that this is a virtue of the account. Someone being forced to be part of sexual activity, against their will, does not have a sexual interaction and thus they do not commit sexual infidelity. If someone is raped, then they are not guilty of sexual infidelity. Similarly, actors who perform a sex scene together, without intending to satisfy any sexual desires, do not have a sexual interaction and thus (I argue) do not commit sexual infidelity.

The challenging case is one like the following. Imagine Lara and Tony have been cheated on by their respective partners. In order to enact revenge, they agree to have sex with each other. They lack any intention to satisfy sexual desire and thus, on my account, they do not have a sexual interaction. This means that they do not commit sexual infidelity. I am willing to bite the bullet here and insist that the intention to produce sexual pleasure is essential to something being a sexual activity. As mentioned above, there are other forms of infidelity. Lara and Tony may still be guilty of emotional, physical or some other kind of infidelity. Also, it is very rare for people

\footnotetext{
23 This is thus a general issue that applies to any case where we need to know a person's intentions in order to judge their behaviour.
} 
to have sex solely for, say, revenge. More typically, they will also intend to experience sexual pleasure, which means that the interaction will be a sexual one. Finally, such a case is highly unusual: most instances of sexual intercourse are for sexual pleasure and thus constitute sexual interactions.

Finally, a clarification. Although I have argued that a lot of things can constitute sexual infidelity, I have said nothing about how morally wrong they are. It is possible that some forms of sexual infidelity are not very wrong at all. These may include sexting with someone, having phone sex with a stranger and using pornography. This will depend, in part, on how wrong one thinks infidelity is. One might think it is always very wrong, so even the least bad form of it is still very bad. Alternatively, one may think that it can range from not very bad at all (and hence easily forgivable) to seriously wrong (and hence close to unforgivable). Determining the relative wrongness of specific forms of infidelity is beyond the scope of this paper. For now, I hope that I have provided a convincing account of what makes something a sexual interaction and thus of what things should, and should not, be considered sexual infidelity.

Acknowledgements Paddy McQueen is very grateful to two anonymous journal reviewers for their helpful comments and questions.

Open Access This article is licensed under a Creative Commons Attribution 4.0 International License, which permits use, sharing, adaptation, distribution and reproduction in any medium or format, as long as you give appropriate credit to the original author(s) and the source, provide a link to the Creative Commons licence, and indicate if changes were made. The images or other third party material in this article are included in the article's Creative Commons licence, unless indicated otherwise in a credit line to the material. If material is not included in the article's Creative Commons licence and your intended use is not permitted by statutory regulation or exceeds the permitted use, you will need to obtain permission directly from the copyright holder. To view a copy of this licence, visit http://creativecommons.org/licen ses/by/4.0/.

\section{References}

Abramson, P.R., and S.D. Pinkerton. 2002. With pleasure: Thoughts on the nature of human sexuality [2nd edition]. Oxford: Oxford University Press.

Ben-Ze'ev, A. . 2004. Love Online: Emotions on the Internet. Cambridge: Cambridge University Press.

Blow, A.J., and K. Hartnett. 2005. Infidelity in committed relationships II: A substantive review. Journal of Marital and Family Therapy 31(2): 217-233.

Bratman, M.E. 1992. Shared cooperative activity. The Philosophical Review 101(2): 327-341.

Bratman, M.E. 2014. Shared agency: A planning theory of acting together. Oxford: Oxford University Press.

Christina, G. 2017. Are we having sex now or what? In Philosophy of sex: Contemporary readings [7th edition], ed. R. Halwani, A. Soble, S. Hoffman, and J.M. Held, 31-38. Lanham, MD: Rowman \& Littlefield.

Collins, L. 1999. Emotional adultery: Cybersex and commitment. Social Theory and Practice 25(2): 243-270.

Goldman, A. 1977. Plain sex. Philosophy \& Public Affairs 6(3): 267-287.

Gray, R. 1978. Sex and sexual perversion. Journal of Philosophy 75(4): 189-199.

Guitar, A.E., G. Geher, D.J. Kruger, J.R. Garcia, M.L. Fisher, and C.J. Fitzgerald. 2017. Defining and distinguishing sexual and emotional infidelity. Current Psychology 36: 434-446.

Morgan, S. 2003. Sex in the head. Journal of Applied Philosophy 20(1): 1-16. 
Nagel, T. 1969. Sexual perversion. Journal of Philosophy 66(1): 5-17.

Negy, C., D. Plaza, A. Reig-Ferrer, and M.D. Fernandez-Pascual. 2018. Is viewing sexually explicit material cheating on your partner? A comparison between the United States and Spain. Archives of Sexual Behavior 47: 737-745.

Portmann, J. 2017. Chatting is not cheating. In The philosophy of sex: Contemporary readings, 7 th ed., ed. R. Halwani, A. Soble, S. Hoffman, and J.M. Held, 85-102. Lanham, MD: Roman \& Littlefield.

Primoratz, I. 1999. Ethics and sex. London: Routledge.

Reuben, D. 1971. Everything you always wanted to know about sex. New York: Bantam.

Rockman, A. 2017. What is cheating? HuffPost/YouGov poll addresses adulterous behaviors. Huffington Post, December $6^{\text {th }}$ 2013. https://www.huffpost.com/entry/what-is-cheating_n_3189080

Scheutz, M., and T. Arnold. 2017. Intimacy, bonding, and sex robots: Examining empirical results and exploring ethical ramifications. In Robot sex: Social and ethical implications, ed. J. Danaher and N. McArthur, 247-260. Cambridge, MA: The MIT Press.

Shaffer, J.A. 1978. Sexual desire. Journal of Philosophy 75: 175-189.

Soble, A. 2006. Sexual activity. In Sex from Plato to Paglia: A philosophical encyclopedia, vol. 1, ed. A. Soble, 15-25. Westport, CT: Greenwood Press.

Soble, A. 2002. Masturbation: Conceptual and ethical issues. In Philosophy of sex: Contemporary readings, 4th ed., ed. A. Soble, 67-94. Lanham, MD: Rowman \& Littlefield.

Solomon, R.C. 1974. Sexual paradigms. Journal of Philosophy 71(4): 336-345.

Whitty, M.T. 2004. Pushing the wrong buttons: Men's and women's attitudes toward online and office infidelity. CyberPsychology and Behaviour 6(6): 569-579.

Woollard, F. 2010. Cheating with Jenna: Monogamy, pornography, and erotica. In Porn - Philosophy for everyone: How to think with kink, ed. D. Monroe, 93-104. London: Blackwell.

Publisher's Note Springer Nature remains neutral with regard to jurisdictional claims in published maps and institutional affiliations. 